\title{
Dona Ivone Lara e terapia ocupacional: devir-negro da história da profissáo
}

\author{
Dona Ivone Lara and occupational therapy: the becoming-black of the \\ profession's history
}

\author{
Jaime Daniel Leite Junior ${ }^{a}$ (D), Magno Nunes Farias ${ }^{a}$ (D), Sofia Martins ${ }^{a}$ \\ ${ }^{a}$ Universidade Federal de São Carlos - UFSCar, São Carlos, SP, Brasil.
}

Como citar: Leite Junior, J. D., Farias, M. N., \& Martins, S. (2021). Dona Ivone Lara e terapia ocupacional: devir-negro da história da profissão. Cadernos Brasileiros de Terapia Ocupacional, 29, e2171. https://doi.org/10.1590/2526-8910.ctoARF2171

\begin{abstract}
$\underline{\text { Resumo }}$
Este ensaio apresenta uma análise das contribuições de memórias negras que perpassam a terapia ocupacional - colocando em tela a história de Yvonne Lara. Yvonne Lara foi enfermeira, assistente social e especialista em terapia ocupacional. A partir dos anos 1940, realizou práticas voltadas para o cuidado de pessoas com transtornos mentais, utilizando a música como atividade terapêutica e o trabalho de articulação com a família e comunidade, na busca de processos de desinstitucionalização dos sujeitos. $\mathrm{O}$ texto aponta a inovação dessas práticas de cuidado, tendo em vista a hegemonia da corrente organicista e asilar que marcava a psiquiatria na época. Defende-se que o resgate de histórias como de Yvonne seja central para a reconstituição histórica da profissão, rompendo com o epistemicídio racista das contribuições do conhecimento dos povos negros. Busca-se visibilizar figuras marginalizadas pelas narrativas oficiais e construir uma diversidade epistêmica no campo, o que denominamos como o devir-negro da terapia ocupacional.
\end{abstract}

Palavras-chave: Racismo, Grupo com Ancestrais do Continente Africano, História da Saúde Pública, Terapia Ocupacional/História.

\section{$\underline{\text { Abstract }}$ \\ This essay presents an analysis of the contributions of black memories within Occupational Therapy field - highlighting the story of Yvonne Lara. Yvonne Lara was a nurse, social worker and specialist in occupational therapy. From the 1940s, her practices aimed to care for people with mental disorders using music as a therapeutic activity and working in cooperation with families and communities in her efforts to deinstitutionalize individuals. The article discusses the innovation of these care practices bearing in mind the hegemony of the organicist current and the asylum-based model that marked psychiatry at that time. It is argued that the salvaging of Yvonne's history is central to the historical reconstruction of the}


profession, turning from the racist epistemicide against the contributions of the knowledge of black people. Herein, we seek to give visibility to individuals who were marginalized by official narratives and to build an epistemic diversity in the field, which we denominate the becoming-black of Occupational Therapy.

Keywords: Racism, African Continental Ancestry Group, History of Public Health, Occupational Therapy/History.

\section{Introduçáo}

Este ensaio surge de debates empreendidos por nós e outras colegas terapeutas ocupacionais, integrantes do Grupo Dona Ivone Lara - Estudos e Pesquisa em Terapia Ocupacional e População Negra ${ }^{1}$, que estão em busca de dialogar saberes e fazeres teórico-práticos sobre questóes étnico-raciais no campo profissional. As pessoas que integram nosso grupo compóem um movimento de renovação crítica e epistemológica da terapia ocupacional, especialmente, para a visibilidade e contemplação das demandas da populaçáo negra.

Grosfoguel (2016) discute que a estrutura epistêmica das universidades ocidentalizadas tem internalizada a lógica racista/sexista do conhecimento, constituída pelos genocídios e epistemicídios do século XVI, implementados pelo projeto colonial e patriarcal. A desqualificação do conhecimento e o quadro de injustiça cognitiva experimentados pelos corpos políticos e geopolíticos dos sujeitos coloniais, mulçumanos e judeus, povos nativos, africanos escravizados e mulheres europeias queimadas acusadas de bruxaria, configuraram a naturalização do privilégio e da inferioridade epistêmica a partir da tradição do pensamento ocidental masculino.

$\mathrm{Na}$ produção de conhecimento em terapia ocupacional, pesquisadores e profissionais de diferentes lugares do mundo (Ambrosio, 2020; Amorim et al., 2020; Beagan \& Etowa, 2009; Farias et al., 2018, 2020; Grenier, 2020; Nicholls \& Elliot, 2019; Martins \& Farias, 2020; Ramugondo, 2000; Steed, 2014) têm trazido debates centralizados na configuração da vida a partir da perspectiva de raça, em uma concepção sociológica das relaçôes sociais, questionando a supremacia branca e pautando as questóes relacionadas à ideologia do racismo.

Nesse sentido, as análises das produções e estudos que se voltam para as questôes estruturais e processuais - raciais, históricas, sociais, políticas e culturais, envolvendo os indivíduos e coletivos negros, e suas interfaces com a terapia ocupacional, têm nos conduzido a uma busca para compreender quais os lugares que pessoas negras ocuparam na consolidação de conhecimento teórico-prático relacionado à profissão. Ou seja, temos nos questionado "Qual foi o lugar da(o) negra(o) e suas contribuiçóes na constituição da história da terapia ocupacional?”.

\footnotetext{
${ }^{1}$ O "Grupo Dona Ivone Lara - Estudos e Pesquisa em Terapia Ocupacional e População Negra” surgiu em outubro de 2016, de maneira independente, reunindo um coletivo de terapeutas ocupacionais de diferentes regiôes do Brasil interessados em se aprofundar no debate de temáticas que envolvem os sujeitos negros. O nome é uma homenagem à Dona Ivone Lara, mulher negra, enfermeira, assistente social e especialista em terapia ocupacional, que foi uma personagem importante para as práticas da terapia ocupacional a partir dos anos de 1940 no Brasil, estando ao lado de Nise da Silveira nas proposiçóes de cuidados humanizados aos sujeitos institucionalizados em manicômios.
} 
Com base nessas indagaçóes, emerge o interesse de compreender e aprofundar na história de Yvonne Lara, uma mulher negra que contribuiu para o desenvolvimento da terapia ocupacional no Brasil, mas que segue sendo invisibilizada em diversos momentos na historiografia da profissão. Ainda que Yvonne Lara estivesse ao lado de Nise da Silveira na proposição de cuidados em um manicômio, pouco se conhece e reconhece sobre a sua importância.

Yvonne Lara teve diferentes nomes. Nasceu Yvonne da Silva Lara e passou a assinar Yvonne Lara da Costa depois de casada ${ }^{2}$. No mundo da música, enquanto sambista, ficou conhecida como Dona Ivone Lara, a Dama do Samba, e, posteriormente, foi consagrada Rainha do Samba (Dona Ivone Lara, 2020; Scheffer, 2016; Burns, 2006; Santos, 2005). No presente texto, optamos por chamá-la de Yvonne Lara e a escolha dessa uniformização se deve ao fato de termos nos aprofundado na sua trajetória como profissional de saúde, especificamente na saúde pública. Ressalta-se também que, para Yvonne, era essencial separar a vida que construiu enquanto profissional da saúde do universo da música, ainda que percebamos o intenso cruzamento destes mundos.

Yvonne Lara foi enfermeira, assistente social e especialista em terapia ocupacional (Scheffer, 2016). Até a década de 1950, a terapia ocupacional não era uma profissão de ensino técnico ou superior no Brasil, vindo a se institucionalizar posteriormente. Naquele momento, terapia ocupacional (também chamada de praxiterapia, terapêutica ocupacional, entre outras nomenclaturas) era a definição de um conjunto de práticas que usavam a ocupação de forma terapêutica (Soares, 1991). Assim, o caráter de especialização se deu pelo fato de Yvonne ter se formado na década de 1940, no Curso elementar de terapêutica ocupacional. Oferecido por Nise da Silveira, o curso foi responsável pela capacitação das intituladas auxiliares de praxiterapia (Silva, 2011; Paranhos, 2018).

Nesta direção, propomos a imersão em sua narrativa, na busca de romper com a sistemática invisibilização das fundamentais contribuiçóes do povo negro. Esse reconhecimento vai ao encontro do que Trouillot (1995), em sua obra Silenciando o passado, apresenta sobre como a produção de conhecimento histórico é mediada por relaçóes de poder, discutindo que, ontologicamente, intelectuais europeus atribuíam às pessoas negras um lugar de incapacidade na produção de obras de valor e destaque. Munanga (2015, p. 31) corrobora tal afirmativa ao fortalecer que a história da África foi negada na historiografia colonial, e "a história do negro no Brasil passou pela mesma estratégia de falsificação e de negação e quando foi contada foi do ponto de vista do outro e de seus interesses". Assim, a história de grupos sociais subalternos é colocada de forma degradada e episódica, sendo central o exercício de identificar e se aprofundar nessas histórias invisibilizadas das narrativas oficiais (Gramsci, 2002).

Adichie (2019, p. 16), em seu livro O perigo de uma história única, discorre que

As histórias importam. Muitas histórias importam. As histórias foram usadas para espoliar e caluniar, mas também podem ser usadas para empoderar e

\footnotetext{
${ }^{2}$ Parte da literatura que acessamos dizia que o nome de registro era Yvonne da Silva Lara e outra parte referia como Yvonne Lara da Costa. Pelas elucidaçôes, agradecemos a Fernanda Jacob, atriz e cantora que interpreta Dona Ivone Lara na peça "Dona Ivone Lara - O musical" e a André Lara, cantor, músico compositor e neto de Dona Ivone Lara.
} 
humanizar. Elas podem despedaçar a dignidade de um povo, mas também podem reparar essa dignidade despedaçada.

Assim, contar, recontar, reelaborar e reconstruir as histórias oficiais (colocadas como únicas) se torna um processo essencial para humanizar, reconhecer e reparar a dignidade de sujeitos ou coletivos que foram fundamentais para a consolidação da sociedade, e, no nosso caso, de práticas que dizem da profissão terapia ocupacional.

Nesta perspectiva, buscamos contribuir com o resgate e fortalecimento das negras memórias que perpassam a terapia ocupacional. Em acordo com Araújo (2004, p. 247), reafirmamos que

[...] precisamos ter orgulho dos feitos de nossos homens e mulheres [negras] que, a despeito do estigma herdado da escravidáo, marcaram seu lugar na nossa história, como cientistas, engenheiros, poetas, escritores, doutores, escultores, pintores, historiadores [e terapeutas ocupacionais].

\section{"Só náo fui aquilo que não quis ser"?": Fragmentos da Vida de Yvonne Lara}

Yvonne Lara nasceu em casa, por um parto realizado com uma parteira, no dia 13 de abril de $1921^{4}$, em Botafogo, Zona Sul do Rio de Janeiro - Brasil. É a primeira filha do casal de músicos Emerentina Bento da Silva e José da Silva Lara. O pai dela faleceu quando a mãe estava grávida da irmá, Elza. Como a família era pobre e o pai era o principal responsável pela renda da casa, este momento foi de grande instabilidade, pairando sobre a mãe o medo de não conseguir suprir as necessidades básicas. A situação se normalizou alguns anos depois, quando Emerentina se casou com Venino José da Silva. Além das duas filhas, o casal teve outras duas crianças, Nilo e Valdir (Burns, 2006).

Os pais de Yvonne se preocuparam muito com sua educação. Matricularam-na no Instituto Profissional Feminino Orsina da Fonseca, internato público, mantido pela Prefeitura do Rio de Janeiro. O colégio era bastante tradicional, reconhecido pelo rigor, severidade e qualidade do ensino ${ }^{5}$. Ela ingressou com 10 anos de idade e só saiu definitivamente quando atingiu a maioridade. Com o cotidiano intenso de atividades, visitava a família quinzenalmente, aos finais de semana. Yvonne tinha aulas de canto e participou do orfeão, tendo uma das melhores vozes do grupo. Neste período, teve a oportunidade de ter aulas com "Dona” Lucília e Zaíra de Oliveira ${ }^{6}$, o que a deixava

\footnotetext{
${ }^{3}$ Trecho da entrevista de Dona Ivone Lara para Burns (2006, p.40).

${ }^{4}$ Em 2021 é comemorado o centenário de Dona Ivone Lara. Assim como o nome, há divergências na literatura sobre sua data de nascimento. André Lara nos elucidou sobre este tópico, apontando que, na realidade, Yvonne Lara nasceu em 1922. A mãe de Yvonne, intencionando que a filha pudesse acessar a escola, alterou os documentos da criança. A partir disso, a família decide reconhecer celebrar o centenário de Dona Ivone Lara duas vezes, em 2021 e 2022.

${ }^{5}$ Conforme Burns (2006), o Orsina da Fonseca foi um colégio voltado para a profissionalização de mulheres, principalmente as de baixa renda, tornando-as mulheres ideais. O objetivo era formar a mulher como mãe, esposa e trabalhadora ao lado do homem, quando necessário, para que pudesse se manter sem humilhaçôes ou dependências. Em 1933, houve uma grande remodelação na escola, com novos professores e diretores. Além disso, disciplinas como geometria, química, física, história natural e língua portuguesa ganharam mais destaque no currículo, que antes era mais voltado para o ensino de habilidades artísticas, datilografia, corte e costura, entre outros.

6 "Dona” Lucília era a professora Lucília Villa-Lobos, também esposa do maestro Heitor Villa-Lobos. O maestro tinha o hábito de ir ver as apresentaçóes do orfeão e Yvonne chegou a cantar sob sua regência. Yvonne também teve aulas com Zaíra de Oliveira, considerada uma das grandes cantoras negras que o Brasil teve. Em 1921, Zaíra foi vencedora do concurso Escola de Música, considerado o mais importante da época, mas, devido à cor da pele, foi impedida de receber o prêmio (Dona Ivone Lara, 2020; Burns, 2006).
} 
muito orgulhosa. Essas experiências e o aprofundamento nos estudos do canto foram desenvolvendo em Yvonne o prazer pela música, começando a compor melodias já naquela época (Burns, 2006). Ela vivia entre dois mundos distintos (Scheffer, 2016), "[...] enquanto no colégio passava os dias estudando um determinado gênero musical, sua teoria e aplicaçóes, nos finais de semana, na casa dos familiares, não abria mão de escutar outro, não apenas distinto, mas, aos olhos da sociedade, quase oposto" (Burns, 2006, p. 36-37), marcado pelo samba, chorinho, jongo, entre outras músicas comuns naquele território.

Burns (2006) relata que, durante o período do colégio interno, houve uma importante marca na vida de Yvonne: o falecimento de sua mãe. Emerentina morreu com 33 anos, devido à hipertensão arterial. Isso, aliado às visitas quinzenais, fragilizou bastante a relação com a família e o internato se tornou central em suas identificaçóes e referências do universo feminino.

Yvonne narrou o grande peso de ser uma menina de apenas 12 anos, negra e órfã de pai e mãe. "Isso cobrava de mim mais do que as garotas dessa idade costumam ser capazes de oferecer". No mesmo ano em que perdeu a mãe, ela viu ser aprovada a Constituição Federal que dava às mulheres direito ao voto e as igualava aos homens em termos de direitos trabalhistas. Era um momento de efervescência no país, em que elas começavam a deixar a posição de subalternas para cobrar reconhecimento e igualdade (Burns, 2006, p. 39).

Então, desde os 12 anos, Yvonne foi lançando mão de estratégias de vivência e sobrevivência, construindo-se independente, dona de seu destino.

Após ter saído do colégio, foi morar na casa de sua tia materna Maria, quem ficou responsável pelas crianças após o falecimento da irmã. Para ajudar com as despesas, que já eram altas antes de sua chegada, seu tio pediu que ela procurasse um trabalho. Bastante resistente em seguir o destino das pessoas ao seu redor e buscando outras ambiçóes para a vida, ela não queria ser operária. Então, certo dia, leu em um jornal sobre a abertura de vagas para a Escola de Enfermagem Alfredo Pinto e decidiu prestar. A escolha pela enfermagem se deu por aquele ser o único curso gratuito e uma oportunidade de mudança da sua realidade socioeconômica. Então, conseguiu fazer um acordo com o tio: eles negociaram que, se ela não passasse no processo seletivo do curso, teria que encontrar um emprego qualquer (Burns, 2006; Santos, 2005).

Yvonne passou entre as 10 primeiras pessoas e isso deu a ela direito a uma bolsa de estudos, a qual ela repassava para a tia para ajudar nas despesas domésticas. O curso estava passando por uma reformulação curricular, com novas diretrizes para a formação profissional e de especialização, em instituições psiquiátricas (Burns, 2006).

Formada e já morando em outro local - agora na casa do tio materno Dionísio, motorista de ambulância e estudioso de música nas horas vagas - foi trabalhar na Colônia Juliano Moreira - Hospital psiquiátrico. A música era algo paralelo, que fazia por lazer nas horas vagas, não a encarando como profissão. O desejo pela música se dividia com o da estabilidade financeira, a possibilidade de ter carteira assinada, formalmente assalariada. Seus projetos de estabilidade financeira, aliados com a afinidade com a área, levaram-na a fazer o curso de assistente social, cursando a primeira 
turma da profissão, que ainda estava sem regulamentação no país (Dona Ivone Lara, 2020; Scheffer, 2016; Burns, 2006; Santos, 2005).

Em 1947, ao término de sua nova formação, foi contratada para trabalhar no Instituto de Psiquiatria do Engenho de Dentro, permanecendo até aposentar, em 1977. Inicialmente, seu trabalho no Instituto era voltado para a elaboração dos relatórios sobre os pacientes; ela percorria grandes distâncias para visitar os familiares das pessoas internadas, buscando construir ações técnicas que envolviam também esta rede. Posteriormente, descrevia o comportamento dos sujeitos em casa, com a família.

$\mathrm{Na}$ sua equipe, estava Nise da Silveira, médica psiquiatra e sua supervisora. Conforme apresentado anteriormente, Yvonne estudou em uma das turmas do Curso elementar de terapêutica ocupacional, ofertado por Nise, obtendo o título de especialista em terapia ocupacional (Dona Ivone Lara, 2020; Burns, 2006; Santos, 2005). De acordo com Scheffer (2016) e Vasconcelos (2000), “assistentes sociais psiquiátricas”, nesse período histórico, tinham reconhecimento pelas atividades desempenhadas e isto era revertido em prestígio social e retorno financeiro. Isso era muito importante para favorecer diversas chances de valorização econômica para essas trabalhadoras.

O amor pelo samba continuou, contudo, com a intensa carga horária de trabalho, foi ficando mais difícil conciliar as duas tarefas. A estratégia de Yvonne foi programar suas férias para fevereiro, momento em que acontecia a grande festa do carnaval. Essa ela não perdia. Já nesta época, final da década de 1940 e início dos anos 50, Yvonne começa a ouvir suas cançóes sendo interpretadas por grandes músicos. Dos seus encontros com grupos de sambistas e carnavalescos que Yvonne conheceu Oscar Costa, o homem que se tornou seu marido. Em 1947, eles se casaram oficialmente (Burns, 2006; Santos, 2005).

Uma das formas de seguir na carreira profissional, mas manter próxima de si sua paixão, foi compor a equipe que programava o "dia para os doentes". Esta atividade reunia diversos pacientes para atividades lúdicas de música. Nessas atividades, que tomavam todo o dia, eram criados espaços para o outro existir, dando lugar para a voz, a dança e a habilidade com instrumentos. O louco era alguém, tinha o que mostrar, era visto, apreciado (Burns, 2006).

Apesar do samba sempre ter sido algo prazeroso e extremamente importante na socialização da vida adulta de Yvonne, foi só depois de aposentada que seguiu carreira de cantora. Mas, isso não quis dizer que ela esteve alheia aos movimentos da época. Devido ao machismo, não era possível - socialmente e culturalmente - que uma mulher fizesse samba. Então, em parte de sua vida de jovem adulta, a estratégia que Yvonne construiu para que se fizesse presente, ainda que com barreiras, foi escrever as cançôes e entregar para que seu primo, Mestre Fuleiro, as apresentassem como dele. Isso foi mudando e, depois de um tempo, Yvonne integrou oficialmente a ala dos compositores da Escola de Samba Império Serrano do Rio de Janeiro, tendo sido reconhecida, inclusive, como a primeira mulher a compor um samba-enredo oficial (Burns, 2006; Santos, 2005).

Sua carreira musical foi tão brilhante quanto a de profissional da saúde. Yvonne, que se tornou também Dona Ivone Lara, foi mãe, fez grandes parcerias na música, gravou diversos discos e foi inúmeras vezes premiada. Foi uma mulher que deixou vários legados, inclusive, para a terapia ocupacional. 


\section{Yvonne e o Devir-negro da Terapia Ocupacional: Inspiraçóes e Caminhos Para o Pensar/Fazer Atual}

É a partir das noções de ausências e reivindicações de presença das contribuiçôes de pessoas negras na historiografia da terapia ocupacional que damos luz à proposta de um devir-negro para o campo, destacando histórias como a de Yvonne. O uso do termo devir-negro é inspirado na proposta de Mbembe (2018). O autor instiga a construção de um mundo comum que reconhece as feridas históricas sofridas pelos negros desde o tráfico atlântico e toda a história de exploração, objetificação e negação de suas humanidades, mas ao mesmo tempo aguça o projeto de um mundo por vir.

...para aqueles que sofreram a dominação colonial ou para aqueles cuja parcela de humanidade foi roubada num determinado momento da história, a recuperação dessa parcela de humanidade muitas vezes passa pela proclamação da diferença. Mas, como se vê em parte da crítica negra moderna, a proclamação da diferença é somente um momento num projeto mais amplo - o projeto de um mundo por vir, de um mundo à nossa frente, cuja destinação é universal, um mundo livre do fardo da raça e livre do ressentimento e do desejo de vingança que toda e qualquer situaçáo de racismo suscita (Mbembe, 2018, p. 315).

O pensar/fazer de terapeutas ocupacionais se desenvolve a partir da narrativa das pessoas em relação às necessidades e desejos ao longo de suas vidas (Galheigo, 2009), e os recursos de terapia ocupacional são elencados de forma contextualizada e significativa para os sujeitos que encontramos e prestamos assistência (Lima, 2003, 2019). Assim, na lógica de um devir-negro, concebemos a possibilidade de favorecer a construçáo de uma terapia ocupacional que tenha como projeto premissas que dialoguem com as problemáticas da população negra, contemplando o reconhecimento da sua memória e contribuiçóes negadas e distorcidas, agendas de pesquisa, discussóes teóricas, combate ao racismo e promoção de vida desse povo. Nesse caminho, compreendemos que se tornará possível a configuração cada vez mais ética de trabalhos que a profissão se propóe, considerando as necessidades e desejos expressos na diversidade de pessoas, demandas e situaçóes que se apresentam a nós.

Nesse sentido, as práticas protagonizadas por Yvonne naquele momento histórico, a partir dos anos 1940/1950, sinalizam aspectos elementares sobre a busca por outras formas de cuidado, que compreendiam o sujeito e as suas expressóes como centro. Em entrevista concedida a Santos (2005, p. 68-69), Yvonne discorre sobre o assunto.

Eu descobri muitos doentes que eram músicos, esquizofrênicos, que ninguém sabia que eram músicos. Muitos que estavam abandonados pela família. A doutora Nise botou uma sala de música com piano, cavaquinho, pandeiro, à tarde, tinha um ensaio geral e eu estava sempre lá, dançando com eles, sambando, cantando com eles. Tinha um doente que era catatônico, mas a doutora Nise ria muito porque ele dizia assim: "Ivone vai ter ensaio hoje?" e depois caía no mundo dele, só conversava comigo. 
Pelo relato de Yvonne, identificamos que ela utilizou de recursos que possibilitaram o alcance das demandas daquele grupo. Suas práticas envolviam desde a ida até a casa dos sujeitos que estavam internados, até o uso da música. Com isso, buscava acessar os sujeitos, articular e viabilizar o retorno para a família, o que podemos ler como processos de desinstitucionalização, ainda que vigorasse, naquela época, a lógica manicomial. De acordo com Scheffer (2016, p. 491), enquanto integrante de um grupo de pioneiras, Yvonne "era responsável por fazer articulação extramuros entre paciente, família e comunidade".

A reflexão sobre esses recursos nos leva a identificar um repertório de atividades apresentados por Yvonne indissociáveis da história e do contexto de sua vida, como a sua própria experiência na música. $\mathrm{O}$ uso da música e o trabalho com as famílias dos sujeitos internados, especialmente naquele tempo, traz à tona suas contribuições para o avanço no cuidado humanizado (Vasconcelos, 2000), na atenção multi/inter/transdisciplinar, e em práticas territoriais, especialmente voltadas à saúde pública, reconhecendo a importância desta prática estar articulada aos saberes/culturas populares. Por isso, parte do nosso exercício é retomarmos Yvonne como uma referência importante, ainda que com os limites da época, numa proposta contra-hegemônica de cuidado.

Em relato para pesquisa de Burns (2006), Yvonne reafirma que, no serviço, ficava à frente das atividades relacionadas à música, como na programação do chamado "Dia para os doentes". Em entrevista, ela diz:

Nesses dias especiais, a gente organizava alguns internos que queriam se apresentar, dançar, cantar, e eram essas as atividades mais estimuladas pelo método da doutora Nise, que começava a ser posto em prática. Então a gente passava o dia inteiro com eles. Tinha um doente, por exemplo, que se chamava Ribamar e pertenceu à Orquestra Tabajara. Outro tinha o apelido de Xerife, e tocava piano muito bem. Âs vezes a gente ficava horas ouvindo (Burns, 2006, p. 58)

Yvonne foi uma profissional que reconheceu a importância do uso das atividades, vinculando-as às expressóes artísticas, recreativas e culturais, e lançou mão delas no trabalho junto à Nise da Silveira em Engenho de Dentro e na Casa das Palmeiras (entidade sem fins lucrativos criada por Nise, em 1956, como extensão dos serviços de Engenho de Dentro). Suas propostas foram inovadoras, acolhendo histórias pessoais e subjetivas dos sujeitos (Vasconcelos, 2000). Isso radicalizou a proposta de tratamento predominantemente daquele período, que eram pautadas na perspectiva sintomatológica, medicamentosa e focada na busca de intervenção clínica-cirurgia (como eletrochoque e cirurgias neurológicas), da psiquiatria tradicional (Soares, 1991; Castro \& Lima, 2007).

Ademais, essas práticas rompiam com uma perspectiva esvaziada das atividades - que muitas vezes eram utilizadas de forma monótona, repetitiva ou voltada para a manutenção da própria instituição na época (Soares, 1991; Castro \& Lima, 2007) para entendê-las como espaços de expressóes dos sujeitos, a partir dos seus desejos, necessidades e criatividade. Em outro relato de Yvonne, essa perspectiva é evidente: 
Tinha o Ribamar, que era catatônico. Vivia lá, esquecido pela família, quase sem falar. Um dia, estávamos ouvindo uma outra doente tocar piano e comecei a cantar. Ele prestou atenção e ficou admirando... Até que me disse que era músico. Depois, vim a saber que tinha sido clarinetista da Orquestra Tabajara. E passou a tocar nas festas do hospital. Melhorou de um dia para o outro. Uma coisa impressionante! Fui à casa dele conversar com os familiares, que passaram a visitálo. E ele ficou curado. Dali a um tempo, saiu de lá bonzinho! (Burns, 2009, p. 8).

É interessante perceber e destacar que se Nise da Silveira tinha como repertório teórico as leituras do psicólogo analítico Carl Jung (Soares, 1991), Yvonne utilizava seu repertório musical como metodologia de intervenção, pautado no saber/cultura popular do samba e enraizado em sua trajetória. Se o caminho de cuidado construído no manicômio de Engenho de Dentro passou pela música, parte considerável disso foi devido ao saber de Yvonne. Foi seu conhecimento técnico e pessoal que evidenciava os efeitos da música no ser humano. Por meio do seu caminhar que os benefícios de uma vida embebida na cultura popular se tornaram compreensíveis.

Assim, mantemos o exercício de refletir que a atuação de Yvonne Lara na terapia ocupacional da época possibilitou a geração de um repertório de recursos e intervenções que puderam, inclusive, ampliar o conjunto de ações que temos como referência no trabalho de Nise da Silveira.

Lima (2019) identifica que, em uma nova direção, a prática da terapia ocupacional enquanto profissão de Ensino Superior atua no campo das possibilidades e recursos, buscando a conexão e agenciamento de experiência, potencialidade da vida e promoção de transformaçôes. Assim, a trajetória de Yvonne, ainda que invisibilizada pela história, foi no passado - e certamente é nos dias atuais - uma referência para a ação em terapia ocupacional. Ainda que num contexto institucional de desumanização e violência, as fissuras provocadas pelo trabalho desenvolvido por Yvonne nos fomenta e informa em diversos caminhos. Seja pela atividade, especialmente a música, usada para promover participação e expressão dos sujeitos institucionalizados, pautadas nas necessidades e desejos desses, ainda que circunscritos nos limites da lógica manicomial; seja pelo trabalho de articulação com as famílias na busca de processos de desinstitucionalização dos sujeitos, que procurava gerar o reestabelecimento da rede familiar, numa lógica extra-muros.

Reconhecemos que esses sejam alguns exemplos, ainda que com limites, de açóes que reinventaram o pensar/fazer do que era entendido e subsidiado como práticas de terapia ocupacional naquela época, que, de forma embrionária, mas transgressora, buscavam romper com o modelo asilar, podendo orientar e inspirar o trabalho terapêuticoocupacional atual, dada a importância contínua de reafirmar a necessidade de um trabalho crítico, fundamentado no sujeito e na experimentação da vida, por meio da criação, da arte, dos encontros, da circulação livre, na busca pela promoção da autonomia, cidadania e ampliação da cultura e no alcance dos desejos dos sujeitos - em uma sociedade sem manicômios.

\section{Consideraçóes Finais: um Manifesto às Várias Yvonnes Laras}

Yvonne Lara é uma figura de resistência em sua trajetória. Mulher negra de origem pobre, em uma sociedade sexista, racializada e socioeconomicamente desigual, buscou construir e dar vida a seus projetos em diversas dimensóes, lidando com os efeitos 
violentos e cotidianos dessa estrutura sociocultural. Realça-se que alguns desses aspectos foram exteriorizados em suas composiçóes, como a música Lamento do Negro:

\section{Canto do negro é um lamento}

Na senzala do senhor...

O negro veio de Angola

Fazendo sua oração

Na promessa da riqueza

Só ganhou a escravidão...

A música é uma denúncia de algo que vivenciava no cotidiano, porém, sem perder a beleza e a possibilidade de anúncio da liberdade, como é percebido na música Sorriso Negro:

\section{Um sorriso negro \\ Um abraço negro \\ Trazfelicidade \\ Negro sem emprego}

Fica sem sossego

Negro é a raiz de liberdade...

Nessa perspectiva, a análise da trajetória de Yvonne evidencia experiências de vida e de uma prática profissional que nos permitiram considerar possíveis contribuiçôes de um devir-negro para a terapia ocupacional, assim como tem sido emergente seu reconhecimento no Serviço Social (Scheffer, 2016). A produção de conhecimento no campo tem trilhado importantes discussões que destacam o objeto de estudo da terapia ocupacional pautado no ser humano em atividade e nos múltiplos cotidianos. Não por acaso, acreditamos que a experiência, os contextos e a história de vida de Yvonne possam ter trazidos elementos importantes para pensar os recursos utilizados pela nossa profissão, como a música - o samba, para promover o alargamento das possibilidades de vida das pessoas que acompanhamos, indo de encontro com os processos estruturais.

Por essa razão, concordamos que a história de Yvonne possibilita o avanço da nossa compreensão em relaçáo à necessidade de iluminar as propostas e a multiplicidade de experiências que os seres humanos em ação vão gerar e produzir com base em histórias singulares de vida. Assim, o devir-negro da terapia ocupacional se encontraria nos momentos de reflexão, análise e criticidade em relação às contribuiçóes que os povos 
negros têm gerado para o campo, especialmente ao apresentar caminhos para a construção de um mundo que está cotidianamente por vir.

Por fim, compreendemos que dizer da história de Yvonne Lara para a terapia ocupacional é um manifesto pelo reconhecimento e resgate das memórias negras - de diversas mulheres negras que colaboraram para a consolidação das práticas que deram vida à profissão. Seu raciocínio, suas abordagens e ações técnicas podem informar a terapia ocupacional, seja para práticas atuais ou ainda para uma reanálise histórica, identificando suas influências para o desenvolvimento da profissão no Brasil. Certamente, Yvonne e muitas outras contribuíram e ainda contribuem para o que foi, e veio a ser, a terapia ocupacional. Buscamos aqui coadjuvar com o exercício de recontar a história, rompendo com o epistemicídio destes sujeitos historicamente subalternizados e, a partir disso, ampliarmos o conhecimento e reconhecimento das diversas influências negras da profissão.

\section{Agradecimentos}

Agradecemos todas as demais integrantes do Grupo Dona Ivone Lara - Estudos e Pesquisa em Terapia Ocupacional e População Negra, que são essenciais para o caminhar deste projeto coletivo. Ainda, agradecemos a Fernanda Jacob e André Lara pelas elucidaçóes referentes à história de Yvonne Lara.

\section{Referências}

Adichie, C. (2019). O perigo da história única. São Paulo: Companhia das Letras.

Ambrosio, L. (2020). Raça, gênero e sexualidade: uma perspectiva da Terapia Ocupacional para as corporeidades dos jovens periféricos (Dissertação de mestrado). Universidade Federal de São Carlos, São Carlos. Recuperado em 1 de agosto de 2020, de https://repositorio.ufscar.br

Amorim, S. G., Martins, S., Leite Junior, J. D., \& Farias, M. N. (2020). “Asfixias sociais” da população negra e questóes para a terapia ocupacional. Revista Interinstitucional Brasileira de Terapia Ocupacional, 4(5), 719-733. https://doi.org/10.47222/2526-3544.rbto36144

Araújo, E. (2004). Negras memórias, o imaginário luso-afro-brasileiro e a herança da escravidão. Estudos Avançados, 18(50), 242-250. https://doi.org/10.1590/S0103-40142004000100021

Beagan, B. L., \& Etowa, J. (2009). The impact of everyday racism on the occupations of African Canadian women. Canadian Journal of Occupational Therapy, 76(4), 285-293. https://doi.org/10.1177/000841740907600407

Burns, M. (2006). Nasci para sonhar e cantar: gênero, projeto e mediação na trajetória de Dona Ivone Lara (Dissertação de mestrado). Universidade Federal do Rio de Janeiro, Rio de Janeiro.

Burns, M. (2009). Nasci para sonhar e cantar: Dona Ivone Lara, a mulher no samba. Rio de Janeiro: Editora Record.

Castro, E. D., \& Lima, E. M. F. A. (2007). Resistência, inovação e clínica no pensar e no agir de Nise da Silveira. Interface, 11(22), 365-376. https://doi.org/10.1590/S1414-32832007000200017

Dona Ivone Lara (2020). Vida: Dona Ivone Lara. Recuperado em 18 de junho de 2020, de http://www.donaivonelara.com.br/vida.php

Farias, M. N., Leite Junior, J. D., \& Amorim, S. S. (2020). Por uma formação e prática antirracista: consideraçóes para a Terapia Ocupacional. Revista Chilena de Terapia Ocupacional, 20(2), 237-247. https://doi.org/10.5354/0719-5346.2020.54658 
Farias, M. N., Leite Junior, J. D., \& Costa, I. R. B. B. (2018). Terapia Ocupacional e população negra: possibilidades para o enfrentamento do racismo e desigualdade racial. Revista Interinstitucional Brasileira de Terapia Ocupacional, 2(1), 228-243. https://doi.org/10.47222/2526-3544.rbto12712

Galheigo, S. (2009). Narrativas contemporâneas: significado, diversidade e contexto. Revista de Terapia Ocupacional da Universidade de São Paulo, 20(1), 8-12. https://doi.org/10.11606/issn.22386149.v20i1p8-12

Gramsci, A. (2002). Cadernos do Cárcere. Rio de Janeiro: Civilização Brasileira.

Grenier, M.-L. (2020). Cultural competency and the reproduction of White supremacy in occupational therapy education. Health Education Journal, 79(6), 633-644. http://dx.doi.org/10.1177/0017896920902515.

Grosfoguel, R. (2016). A estrutura do conhecimento nas universidades ocidentalizadas: racismo/sexismo epistêmico e os quatro genocídios/epistemicídios do longo século XVI. Estado e Sociedade, 31(1), 2549. https://doi.org/10.1590/S0102-69922016000100003.

Lima, E. M. F. A. (2003). Desejando a diferença: considerações acerca das relaçôes entre os terapeutas ocupacionais e as populaçóes tradicionalmente atendidas por estes profissionais. Revista de Terapia Ocupacional da Universidade de São Paulo, 14(2), 64-71. https://doi.org/10.11606/issn.22386149.v14i2p64-71

Lima, E. M. F. A. (2019). Uma perspectiva ético-estético-política para as atividades em Terapia Ocupacional. In C. R. Silva (Org.), Atividades humanas e Terapia Ocupacional: saber-fazer, cultura, politica e outras resistências (pp. 97-127). São Paulo: Hucitec.

Martins, S., \& Farias, M. N. (2020). Práticas de terapia ocupacional e contexto sociocultural: caso de uma menina negra. In L. C. C. Gradim, T. N. Finarde \& D. C. M. Carrijo (Orgs.), Práticas em terapia ocupacional (pp. 32-37). Barueri: Manole.

Mbembe, A. (2018). Crítica da razão negra. Paris: Éditions La Découverte.

Munanga, K. (2015). Por que ensinar a história da África e do negro no Brasil de hoje? Revista do Instituto de Estudos Brasileiros, (62), 20-31. https://doi.org/10.11606/issn.2316-901X.v0i62p20-31

Nicholls, L., \& Elliot, M. L. (2019). In the shadow of occupation: Racism, shame and grief. Journal of Occupational Science, 26(3), 354-365. https://doi.org/10.1080/14427591.2018.1523021

Paranhos, T. (2018). Dona Ivone Lara: muito além do samba. Taís Paranhos - Jornalista e professora. Recuperado em 16 de junho de 2020, de https://www.taisparanhos.com.br/2018/04/dona-ivonelara-muito-alem-do-samba.html

Ramugondo, E. (2000). The experience of being an occupational therapy student with an underrepresented ethnic and cultural background (Masters dissertation). University of Cape Town, Africa do Sul.

Santos, K. (2005). Dona Ivone Lara: voz e corpo da sincopa do samba (Tese de doutorado). University of Geórgia, Geórgia.

Scheffer, G. (2016). Serviço Social e Dona Ivone Lara: o lado negro e laico da nossa história profissional. Serviço Social \& Sociedade, (127), 476-495. http://dx.doi.org/10.1590/0101-6628.081.

Silva, J. O. M. P. (2011). A arte na terapêutica ocupacional de Nise da Silveira (Tese de doutorado). Universidade Estadual de Campinas, Campinas.

Soares, L. B. T. (1991). Terapia Ocupacional: lógica do capital ou do trabalho? Retrospectiva histórica da profissão no Estado brasileiro de 1950 a 1980. São Paulo: Hucitec.

Steed, R. (2014). The effects of an instructional intervention on racial attitude formation in Occupational Therapy students. Journal of Transcultural Nursing, 25(4), 403-409. https://doi.org/10.1177/1043659614523471

Trouillot, M. R. (1995). Prefácio. In M. R. Trouillot. Silencing the past: power and the production of history (pp. 27-28). Boston: Beacon Press.

Vasconcelos, E. M. (2000). Saúde mental e Serviço Social: o desafio da subjetividade e da interdisciplinaridade. São Paulo: Cortez. 


\section{Contribuiçáo dos Autores}

Todos os autores contribuíram na idealização, redação e revisão final do texto, aprovando sua versão final.

\section{Fonte de Financiamento}

Coordenação de Aperfeiçoamento de Pessoal de Nível Superior - Brasil (CAPES) - Código de Financiamento 001; Fundação de Amparo à Pesquisa do Estado de São Paulo - FAPESP.

\section{Autor para Correspondência}

Jaime Daniel Leite Junior

e-mail: leitejrjd@gmail.com

\section{Editora de seçáo}

Profa. Dra. Adriana Miranda Pimentel 